\title{
The Structure of the Library Market for Scientific Journals: The Case of Chemistry
}

\section{Stephen J. Bensman}

In this paper, the author analyzes the skewed distributions of price and scientific value that constitute the structure of the library market for scientific journals, using chemistry as a test case. A numerical index constructed from a survey of Louisiana State University chemistry faculty and total citations taken from the Science Citation Index Journal Citation Reports were utilized as measures of scientific value. Methodological problems arise from the skewed distributions customary in library research. The major findings are (1) that scientific value does not play a role in the pricing of scientific journals and (2) that little relationship consequently exists between scientific value and the prices charged libraries for scientific journals. Libraries have the opportunity to implement a massive restructuring of their serials collections. A software package named the Serials Evaluator is described. Under development at Louisiana State University, it is software for the automated selection of joumals for cancellation and remote access through document delivery.

\section{The Problem}

Librarians live in a world of highly skewed statistical distributions. Virtually everything they see or touch in their work is affected by such distributions. These distributions lead to the fact that a small minority of agents account for the vast majority of events. Some good rules of thumb are that $10 \%$ of the subjects will be responsible for some $40 \%$ to $50 \%$ of the observed objects, and $20 \%$ will cause about $60 \%$ to $80 \%$. This phenomenon has been documented in-among othersthe following areas: authorship of articles and books; the distribution of articles on a given subject over journals; citations to persons, articles, journals, and academic departments; and the circulation of library materials. Of particular interest in these distributions is what can be termed the zero or random class, which can constitute up to $40 \%$ of a given universe of possible active agents. Examples of this class are potential authors who never or rarely publish, articles that are never or rarely cited, and library materials that never or rarely circulate. Given their nature, these skewed distributions appear to be stable over time (Bensman 1982; Bensman 1985).

Highly skewed distributions are not

Stephen J. Bensman is Special Projects Librarian, Troy H. Middleton Library, Louisiana State University, Baton Rouge (e-mail: notsjb@lsuvm.sncc.lsu.edu). The author wishes to thank Professor James Geaghan, Department of Experimental Statistics, Louisiana State University, Baton Rouge, for his valuable advice and assistance. Manuscript received October 31, 1995; accepted for publication January 24, 1996. 
limited to library science but are also found in such diverse areas as biology, economics, geography, and linguistics. Therefore it is not surprising to find that journal prices are also extremely skewed. This distributional characteristic of journal prices is obvious when journal prices are ranked in descending order by Library of Congress Classification (LCC) subject class. Analysis of the data presented in the 1995 "U.S. Periodical Price Index" (Alexander and Carpenter 1995) shows that the average price of a U.S. periodical per LCC subject class ranges from $\$ 628.89$ in $Q$ (Science) to $\$ 28.18$ in A (General Works) and that-after the average prices are summed-the top two classes Q (Science) and $T$ (Technology), or $10.5 \%$ of the nineteen classes, account for about $41 \%$ of the summed average prices. When the average prices are aggregated into total prices by multiplying them by the number of periodicals in each class, the skew becomes even more pronounced, and class $\mathrm{Q}$ (Science) alone represents $48.8 \%$ of the total cost of the sample.

The highly skewed nature of journal prices received quite a bit of publicity in the late 1980s when it was revealed in a number of studies conducted at academic libraries of their serials expenditures. The authors of these studies found a typical pattern whereby $10 \%$ of the titles were responsible for $50 \%$ of the serials budget, and this pattern was verified at institutions as diverse as Kent State, the University of Hawaii, Clemson, the University of Michigan, and Louisiana State University (LSU). At the latter institution titles costing $\$ 80$ or more constituted only $20 \%$ of the subscriptions but $72 \%$ of the serials expenditures. However, more disturbing was the fact that serials costs were also highly skewed when analyzed in terms of publishers. The LSU study revealed that the top fifty publishers whose titles cost the university $\$ 2,000$ and more accounted for only $10 \%$ of the serials titles but almost $50 \%$ of the serials budget. Of these fifty publishers the top four-Elsevier, Springer, Pergamon, and Plenum-received some $23 \%$ of the money LSU spent on serials (Hamaker 1988; Hamaker 1987). Similar results were obtained in studies at the University of Michigan (Dougherty and Johnson 1988).

The seemingly disproportionate share of serials budgets being soaked up by a few publishers provoked outrage within the library community. Matters were not helped by the fact that many of these publishers were foreign and responsible for a large share of the inflationary price increases ravaging library materials budgets. Hamaker $(1988,211)$ berated the foreign publishers for selling American research back to American libraries at premium prices and accused them of "information colonialism." Meanwhile, Dougherty and Johnson (1988) insinuated that publisher profit was the driving force behind serials prices, hinting openly that "the small group of publishers who dominate commercial publishing have created an oligopoly." The outrage culminated in two research reports and a series of resolutions sponsored by the ARL (Association of Research Libraries 1989). In the first report, Economic Consulting Services, Inc., analyzed the pricing practices of four commercial publishers-Elsevier, Pergamon, Springer, and Plenum-and concluded that this group had increased subscription prices at a much faster rate than the rate at which their costs had increased. It recommended that the library community encourage new entrants into serials publishing and stimulate greater competition among publishers. In the second report Okerson outlined the burgeoning serials crisis as resulting from five basic causes: (1) the explosion in the number of serials titles; (2) the increasing size and frequency of many serials titles; (3) the concentration of these increases in the most expensive fields, particularly the sciences; (4) the key role of commercial, profit-seeking, international publishers in the production of serials, particularly in the scientific fields; and (5) the movement of monetary exchange rates and the use by publishers of differential regional prices to the detriment of North American Iibraries. Okerson then recommended that the ARL should advocate: (1) the transfer of the publication of research results from serials produced by commercial publishers to existing noncommercial channels, 
specifically encouraging the creation of innovative nonprofit alternatives to the traditional commercial publishers and (2) policy changes by university administrations and granting agencies for promotion, tenure, and funding, so as to minimize pressure for excessive publication. The conclusions and recommendations of the two reports were basically adopted in a series of resolutions by the ARL membership, although the one on excessive publication appears to have been toned down to that the "ARL form a partnership with scholarly groups to examine the scholarly publishing process and to find ways to manage the explosion in research and knowledge and the concomitant explosion in publishing." All in all, it was a breathtaking stand against natural and socioeconomic forces, some of the latter of which had been developing for centuries.

However, the problem might not lie in the skewed distribution of journal prices. Skewed distributions are so common in nature and society that in a certain sense being angry at one is almost akin to being upset that the stars distribute themselves unevenly across the universe in galaxies. Moreover, skewed socioeconomic distributions are so tenacious and powerful that any attempt to hammer them artificially flat runs the risk of ending in failure and disaster. The problem might lie in the relationship among the various skewed distributions, and for libraries the serials problem boils down to the following: It is known that not only are the prices of serials highly skewed, but so are the measures of their quality and utility, such as citations and library circulation. If the prices of journals are highly correlated with the measures of their quality and utility, then libraries are in a locked system, and any serials-cancellation project must fail. This is because the library will be forced to keep the $20 \%$ of the serials that consume $80 \%$ of the serials budget, and-if the correlations are high enough-it is theoretically possible to cancel the entire zero or random class or up to $40 \%$ of the collection without saving a penny in subscription costs. There is anecdotal evidence that this might be the case. Dougherty and Johnson $(1988,29)$ used the European
Journal of Pharmacology as an example of a commercial publisher's raising the price of a periodical with a strong citation impact factor, and a survey of ARL directors by the Journal of Academic Librarianship evoked the following response (Dougherty and Barr 1988, 8):

Every study we've done or seen indicates that high cost and high use are linked; and this limits our power to drop expensive journals, even where cooperation is assured. The publishers know what they are doing when they price their core journals.

It is my intention to explore the relationship among the various skewed distributions composing the library market for scientific journals, using chemistry as a test case.

\section{The Database}

The starting point for the construction of a database to analyze the library market for chemistry journals was a survey of the faculty of the Louisiana State University Department of Chemistry on their serials needs. This survey was conducted in April 1993 as a pilot study for a serials-cancellation project. Twenty-five persons, or roughly $71 \%$ of approximately 35 professors and instructors, responded to the survey. Here it should be emphasized that only the Department of Chemistry was surveyed; the Departments of Biochemistry and Chemical Engineering were not included in the pilot study. This omission will later be seen to have had statistical consequences. It should also be noted that there were organizational connections between the faculties of the Departments of Chemistry and Biochemistry. One person served as distinguished professor in both departments, while an associate professor in the Department of Chemistry was also a member of the adjunct faculty of the Department of Biochemistry.

In the survey, members of the chemistry faculty were asked to identify those serials important to them for research and teaching purposes from the entire serials universe, without restricting themselves to the ones on subscription at LSU. The first thing that was done with the sample of serials resulting from this request was to counteract the effects of Garfield's law 
of concentration within it by restricting it in terms of subject coverage. Garfield $(1979,21-23)$ presents his law by picturing the journal literature of a discipline as a comet. In this depiction the nucleus of the comet represents the core of the relatively few journals that publish the overwhelming majority of the material on the discipline important enough to be cited, whereas the tail of the comet is the exponentially increasing number of journals publishing an ever-decreasing quantity of significant papers on the subject. However, according to Garfield, there is a considerable amount of disciplinary overlap, and his law of concentration states the "the tail of the literature of one discipline consists, in large part, of the cores of the literatures of other disciplines." In his opinion, this overlap is so great that the interdisciplinary core for all science disciplines involves no more than 1,000 journals and perhaps as few as 500 .

Garfield's law of concentration confronts the researcher with two major statistical problems closely related to each other. First, serials from disparate disciplines differ markedly from each other in such quantitative measures as citation rates, library usage, price, and size. Therefore, mixing journals from different disciplines in the same sample nullifies significant statistical relationships. This phenomenon was demonstrated by Stankus and Rice (1982) and Rice (1979) in analyses of the correlations between SCI-citation frequency and scientific-journal usage at the State University of New York at Albany (SUNYA). In their work they showed that whereas no significant correlations were found when SUNYA usage was tested against SCI-citation frequency on a global basis, i.e., for science as a whole without regard to individual disciplines, excellent and good correlations emerged between these two variables as soon as the journals were segregated according to subject, scope, purpose, and language.

The second major statistical problem resulting from Garfield's law of concentration is that it is virtually impossible to obtain an uncontaminated sample of serials from a single scientific discipline. This derivative from Garfield's law is evident in the work of ISI on the classification of joumals into subject categories. Each year the institute applies cocitation and cluster analysis to its database to map the disciplinary topology of science (Small and Garfield 1985), and it often places serials into more than one of the subject categories classifying the journals covered by the SCI. A statistical consequence of the interdisciplinary nature of science combined with the highly skewed distributions of its measures is the inherent risk of an extreme outlier in a data set or--in the definition of Barnett and Lewis (1984, 4) - "an observation (or subset of observations) which appears to be inconsistent with the remainder of that set of data." These outliers might often be the result of a sample of journals from one subject distribution containing contaminants from another subject distribution (Bamett 1978; Barnett and Lewis 1984, 1-44). Due to the operation of Garfield's law of concentration, such outliers cannot be excluded on logical grounds, and it is only possible to explain-where feasibletheir effect on the statistical results.

The LSU chemistry faculty certainly followed the dictates of Garfield's law of concentration in their responses to the serials survey, selecting journals in numerous ISI subject categories. Among the ISI subject categories of the journals chosen by them were the following: Engineering, Electrical, and Electronic; Environmental Sciences; Geosciences; Materials Science, Ceramic; Nutrition and Dietetics; Physics; and Radiology and Nuclear Medicine. As an example of the statistical difficulties possible from retaining all the titles, one of the 25 respondents picked the prestigious New England Journal of Medicine-a result that certainly would have been different had the 25 respondents been medical doctors. To control for the effects of Garfield's law of concentration, it was first decided to restrict the sample to those titles selected by the LSU chemistry faculty and classified by ISI in the general subject category Chemistry. However, because there was not enough overlap to create a viable sample, one was forced to run the increased risk of contaminants and extend the sample to all 
branches of chemistry, including chemical engineering and crystallography. The SCI subject class Spectroscopy was also included due to the emphasis of the LSU Department of Chemistry on it, even though this discipline is generally considered part of optics within physics.

The titles chosen for inclusion in the database were then subjected to technical analysis via the OCLC Online Computer Library Center, Inc., cataloging system in order to clarify their 1993 compositional status and their history. With respect to compositional status the main goal was to check whether a given serial title consisted of one unit or was divided into sections. The purpose of historical analysis was to trace the various title changes, divisions into sections, and combinations into units of a serial back to the year of its establishment. The primary determinant of whether a serial remained the same publication through all these vagaries was the consistency and continuity of the volume numbering. During the course of the data collection, it became necessary to establish a policy of aggregating all the sections of a serial into one unit. Thus, the five sections of the Journal of the Chemical Society-Chemical Communications, Dalton Transactions, Faraday Transactions, Perkins Transactions 1 , and Perkins Transactions 2 -were treated as a single entity in terms of statistical measures. The result from the preceding steps was a serials database containing 154 observations.

Three quantitative variables were employed to measure the scientific value of the serials in the database. The first was called faculty score, and it was developed from information provided by the respondents to the April 1993 serials survey of the LSU Department of Chemistry. In this survey the chemistry faculty members were asked to prioritize their serials needs by identifying the titles important to them and dividing these titles into the three following groups: (1) those titles used frequently enough for teaching purposes to be needed on campus; (2) those titles used frequently enough for research purposes to be needed on campus; and (3) titles for both teaching and research that could be located off campus and satisfactorily ac- cessed through a rapid document delivery service. Within each group the faculty members were requested to limit themselves to ten titles, and for the first two groups they were asked to rank the titles in descending order of importance from 1 to 10 . The faculty members also estimated the frequency with which they thought the titles would be used.

Inspection of the responses to the April 1993 survey did not reveal whether the LSU chemistry faculty as a whole regarded teaching or research as more important with respect to serials. As a result, it was decided to ignore this distinction, regroup the titles as to whether they were needed on campus or could be located off campus, and eliminate any double counting of titles by individual faculty members. Then each title was assigned 10 points for every faculty member who chose it and another 10 points for every faculty member who wanted it on campus. If a title was placed in the off-campus group by a faculty member, it was given no extra points. The titles were also allocated points on how each faculty member ranked them, with 10 points given every rank of $l$, down to 1 point given every rank of 10 . If a faculty member chose more than ten titles and ranked titles 11 and lower, these titles were given 10 points for being chosen but no rank points. Finally, titles were assigned points on the faculty estimates of the frequency with which they would be used: 10 points for each faculty estimate of monthly or more often; 5 points for each faculty estimate of less than monthly up to yearly; and 1 point for each estimate of yearly or less often. Faculty members usually did not distinguish among the different sections of a serial, but where they did, the title was given the higher of the sectional scores. Moreover, where a faculty member scored a title twice-once for teaching, once for research-the serial was given the higher of the two scores if these were different. Under this system the highest number of points a faculty member could give a title was 40 , and the maximum score a title could achieve was 1,000 . The Joumal of the American Chemical Society came closest to this maximum with a faculty score of 755 . 
The remaining quantitative variables for establishing the scientific value of a serial were two citation measures, total citations and impact factor, taken from the 1993 Science Citation Index Journal Citations Reports (SCI JCR 1993). However, before one can fully understand these variables, it is necessary to understand the ISI concept of a source item, which is a research article, review article, or technical note published in any of the journals covered not only by the SCI but also by ISI's other two indexes: the Social Sciences Citation Index (SSCI) and the Arts \& Humanities Citation Index (AdHCI).

With the source item concept in mind, the variable total citations can be defined as the total number of references received by a serial in the database from Source Items processed by ISI for the $S C I, S S C I$, and $A \dot{d} r H C I$. Given Garfield's law of concentration, this variable can be regarded as measuring the importance of a serial to all fields of human knowledge. Here it must be noted the SCI JCR does not combine journal citation counts on the basis of "lineage" except where a title change does not affect a journal's alphabetical position, nor does it combine the citation counts of the different sections of a journal (SCI JCR 1993, 7). However, for the total citations measure utilized in this paper, it was decided to aggregate the counts of a periodical's sections and their backfiles due to the following reasons: (1) the LSU chemistry faculty usually did not distinguish among the different sections of a journal; (2) it was desired to capture the full historical significance of a journal; and (3) the complex divisions and recombinations of a serial over its past often made it impossible to allocate its historical citations among its present sections. The variable impact factor represents an attempt by ISI to create a normalized measure of value by controlling the citation frequency of a serial for age and size. This is done by limiting the backfile of a serial to the two years preceding the processing year of the $J C R$ and then dividing the references to this two-year backfile by the number of Source Items in it to create an average citation rate per article. When required by the policy of aggregating journal sections and their backfiles into single units, the necessary adjustments were made to the appropriate impact factors in the 1993 SCI JCR.

Besides measures of scientific value, the database constructed for this article also contains a quantitative variable establishing the economic worth of the serials in it. This variable was simply called "price" and was the subscription price paid in U.S. dollars during 1993 by institutions in the U.S. international area. Where all the sections of a serial were offered in a package deal, the package price was used due to the policy of section aggregation. For the most part the prices were taken from the 1993 Faxon Guide to Serials, which was supplemented-when necessary-by the 1993-94 EBSCO Librarians' Handbook and the 1993 Swets Serials Catalogue, as well as by the 1993 and 1994 Books in Print. One commercial publisher had no standard listings for its journal prices, which were only found in Dutch guilders at the back of the Swets Serials Catalogue; they were converted into U.S. dollars at the exchange rate at the close of the first day of business of 1993 as published in the Wall Street Journal.

To complete the database for this study, variables were developed for measuring certain characteristics thought to be important with respect to the scientific and economic value of serials. Three of these variables were quantitative variables like the preceding ones and can be briefly described. First, there is one called "source items," which was intended as a measure of the size of the serial. Defined by ISI, it is the number of research articles, review articles, and technical notes published in the database's periodicals during 1993. The data for this variable were obtained from the 1993 SCI JCR. The second variable was called "journal age," and its purpose is clear from its name. This variable was derived by having the computer subtract from 1993 the year of the periodical's establishment found during the historical analysis of the title via the OCLC cataloging system. The third variable was called "libraries holding," and it, too, was acquired from 
OCLC, which during operating year 1993-94 had 18,168 member libraries in 61 countries and territories (OCLC n.d., 6,26 ). Each OCLC cataloging record lists the number and abbreviations of the libraries holding the item, and the key serials records are in the successive entry form where a new record is input every time the title changes. The libraries holding data were taken from information on the catalog record for the title segment of the serial current in 1993 after carefully screening for duplicate records and hbrary holdings. Where different concurrent sections of a serial were unevenly held by libraries, the serial was given the highest libraries holding number upon aggregation of the sections into one observation. Even though some of the listings might represent subscriptions canceled by libraries and the overwhelming majority of the listed libraries were located in the United States despite OCLC's claims to international coverage, the libraries holding variable is considered a good estimate of the library market for these periodicals. Given the astronomical costs involved, libraries must represent the vast bulk of the market for most of these chemistry journals.

The final two variables in the serials database for this paper are qualitative or categorical variables intended to describe the nature of the publishers of the chemistry periodicals. Of these variables the first was called "publisher type" and denotes whether a given serial was issued by an association or by a commercial enterprise. The second was named "country of origin," and it designates whether the publisher was located in the United States or was foreign. Information for the qualitative variables was obtained from the same sources as price. With one Canadian and a few Japanese exceptions, all the foreign publishers were Western European.

\section{The Distribution of The QuANTITATIVE VARLables}

Examination of table 1 reveals that all the quantitative variables in the database are highly skewed in the pattern customary for library data. To construct this table, the observations for each variable were first arrayed in descending order and then divided into four classes whose limits were defined by the highest observation, the quartiles, and the lowest observation. By definition each class thus contains approximately $25 \%$ of the titles measured by the variable under consideration. In every case class 1 , containing the observations with the highest values, accounts for more than half of the variable total, ranging from $51 \%$ of the total ages of the serials to $80.2 \%$ of the total citations received by them. This percentage uniformly decreases for every variable as one descends the order, until class 4 , with the lowest values, is responsible for a relatively minute portion of the variable totals, extending for $1.8 \%$ of all the citations given the serials in the sample to $8.9 \%$ of the libraries holding them.

Given the results summarized in table 1 , it is not surprising that Shapiro-Wilk tests resoundingly rejected ( $p=0.0001$ ) for all variables the null hypothesis that the sample data were drawn from normally distributed populations. This is a matter of great concern, because markedly non-normal data might lead to incorrect conclusions in inferential statistical analyses as well as have a biasing effect on correlation coefficients and the more sophisticated procedures based upon such coefficients (Hatcher and Stepanski 1994, 110). Many statistical techniques are based upon the assumption of normal distributions, and, when dealing with data such as those of the chemistry serials, the researcher is confronted with a basic decision: either (1) rely upon nonparametric procedures, which are distribution free and resistant to outliers, or (2) prepare the variables for more powerful parametric treatment through their proper mathematical transformation. It was decided to opt for the latter course.

The first step in deciding upon the proper transformation was to analyze the frequency distributions of the variables to determine whether they matched any single probability distribution. As part of this process, histograms of the variables were constructed, and they all turned out 


\section{TABLE 1}

Percentage Distribution of Quantitative Variables OVER CLASSES DEFINED BY QUARTILES

\begin{tabular}{|c|c|c|c|c|}
\hline & Class 1 & Class 2 & Class 3 & Class 4 \\
\hline \multicolumn{5}{|l|}{ Faculty Score } \\
\hline Quartile limits & $111-755$ & $50-110$ & $33-50$ & $10-32$ \\
\hline $\begin{array}{l}\text { Percentage of } \\
\text { variable total }\end{array}$ & 62.5 & 20.6 & 11.1 & 5.8 \\
\hline \multicolumn{5}{|l|}{ Total Citations } \\
\hline Quartile limits & $11,685-231,324$ & $3,303-11,586$ & $1,533-3,285$ & $255-1,526$ \\
\hline $\begin{array}{l}\text { Percentage of } \\
\text { variable total }\end{array}$ & 80.2 & 13.4 & 4.6 & 1.8 \\
\hline \multicolumn{5}{|l|}{ Impact Factor } \\
\hline Quartile limits & $3.018-37.885$ & $1.730-2.952$ & $1.049-1.697$ & $0.111-1.035$ \\
\hline $\begin{array}{l}\text { Percentage of } \\
\text { variable total }\end{array}$ & 61.9 & 19.4 & 12.2 & 6.4 \\
\hline \multicolumn{5}{|l|}{ Price } \\
\hline Quartile limits & $1,360,00-9,563.87$ & $725.00-1,350.00$ & $408.00-715.00$ & $46.00-402.00$ \\
\hline $\begin{array}{l}\text { Percentage of } \\
\text { variable total }\end{array}$ & 62.0 & 21.0 & 11.9 & 5.1 \\
\hline \multicolumn{5}{|l|}{ Source Items } \\
\hline Quartile limits & $563-3,916$ & $261-551$ & $100-257$ & $5-96$ \\
\hline $\begin{array}{l}\text { Percentage of } \\
\text { variable total }\end{array}$ & 67.8 & 20.1 & 9.2 & 2.9 \\
\hline \multicolumn{5}{|l|}{ Joumal Age } \\
\hline Quartile limits & $39-161$ & $28-38$ & $21-28$ & $3-21$ \\
\hline $\begin{array}{l}\text { Percentage of } \\
\text { variable total }\end{array}$ & 51.0 & 22.7 & 17.6 & 8.8 \\
\hline \multicolumn{5}{|c|}{ Libraries Holding } \\
\hline Quartile limits & $528-1,728$ & $319-519$ & $229-318$ & $55-225$ \\
\hline $\begin{array}{l}\text { Percentage of } \\
\text { variable total }\end{array}$ & 51.6 & 23.4 & 16.2 & 8.9 \\
\hline
\end{tabular}

Titles are arrayed in descending order, and each Title, Class contains approximately $25 \%$ of the titles. Each variable has 154 titles except for Source Items, which has 151 titles.

remarkably similar. Interestingly enough, they closely resembled the histogram presented by Lotka (1926) in his seminal paper in bibliometrics on the frequency distribution of scientific productivity. In his paper, Lotka noted that frequency distributions of this general type have a wide range of applicability to a variety of phenomena. The histogram for faculty score is shown in Figure 1 as a typical example of those found for all the variables in the chemistry-serials data set. It should be pointed out that the isolated bar at 755 is not an outlier but represents the Journal of the American Chemical Society and, thus, the essence of the entire system.

Skewed distributions are extremely common in nature, and for determining which probability distribution describes the frequency distributions of the variables in the chemical-serials database, a statistical manual was utilized. This manual was developed by the British zoologist Elliott (1977) for analyzing samples of 


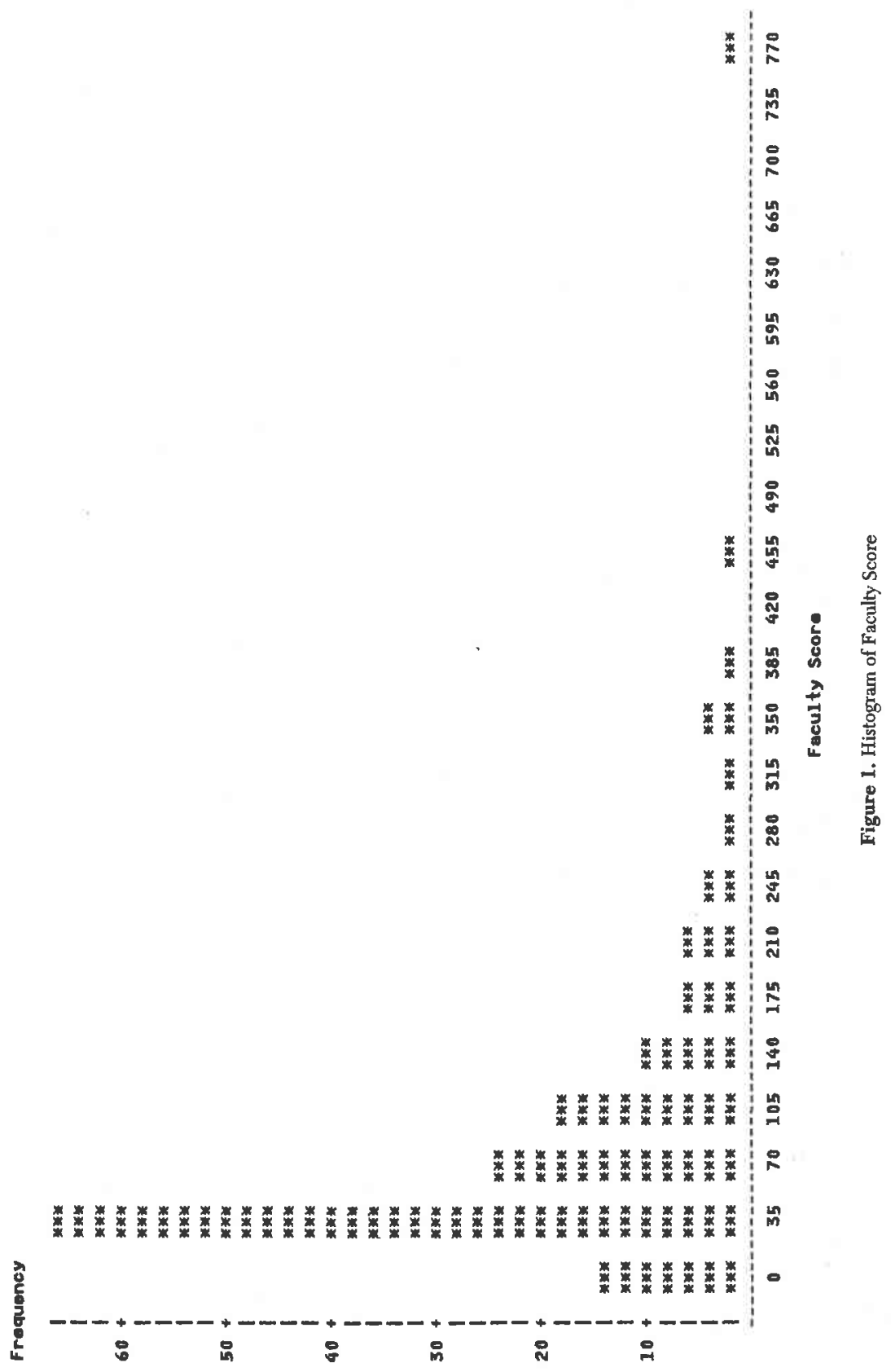


benthic invertebrates gathered in the English Lake District. On the basis of Elliott's work it is possible to posit three basic ways in which phenomena distribute themselves over observations. One of these ways is random distribution, whereby there is no regularity to the manner in which the phenomena distribute themselves. The random pattern is best described by the Poisson distribution, and its distinguishing statistical characteristic is that the variance equals the mean. Another distributional model is regular distribution, and here the phenomena tend to disperse themselves evenly or uniformly over the observations. This model is described by the positive binomial distribution, whose distinguishing statistical characteristic is that the variance is less than the mean. The final theoretical way in which phenomena can arrange themselves is contagious distribution. With contagious distribution the phenomena concentrate themselves on a relatively few observations, and the chances are that where you find one example of a phenomenon, you will find another. There are diverse patterns of contagious distributions, and a number of mathematical models have been put forward to describe them. The most useful of such models is the negative binomial distribution, and its distinguishing statistical characteristic is that the variance is greater than the mean. With respect to bibliometrics, Price (1976) considered the negative binomial distribution to be descriptive of the Matthew Effect propounded by Merton (1968) as an explanation of the manner in which rewards are allocated among scientists. Derived from the Gospel according to St. Matthew (13:12) - " For to those who have, more will be given, and they will have an abundance; but from those who have nothing, even what they have will be taken away" - the Matthew Effect embodies a system of cumulative advantage that appears to be operative in the highly skewed distributions of authorship, citations, library usage, etc. (Bensman 1982; Bensman 1985).

To determine which probability distribution was proper for the variables in the chemistry-serials database a chi-square test was used to see whether the condition of the Poisson distribution was met. The null hypothesis was set that the ratio of the variance divided by the mean, or V/M ratio, equaled 1 , and for every variable this null hypothesis was rejected with a zero probability that this was so. This result established that all the V/M ratios were significantly different from 1 , and inspections of these ratios showed that every one was greater than 1, disproving the possibility of the positive binomial distribution. Because all the variances were demonstrably greater than their respective means, it was decided that the chemistryserials variables were probably following the negative binomial distribution. According to Elliott (1977, 33), the proper transformation for such variables is the logarithmic transformation, and in this paper $\log e$ or $\ln$ is utilized when such transformations are required. This policy is in conformance with the advice of the late Charles Winsor, who frequently prescribed the logarithmic transformation of all natural counts-no matter what the source-before their analysis, because the number of times the prescription harms the patient are few in comparison to the cures (Acton 1959, 223).

\section{The Measurement of SCIENTIFIC VAlUE}

In this approach to the measurement of scientific value, value is postulated as a construct of the human mind. Therefore value follows Bishop Berkeley's maxim that "to be is to be perceived." The thing being evaluated might possess objective attributes that might affect its subjective evaluation, but the final arbiter in matters of value is the human mind. The viewpoint adopted in this paper was succinctly stated by Cartter $(1966,4)$, who directed the 1964 American Council on Education (ACE) assessment of quality in U.S. graduate education. Defending peer ratings as a proper methodology for assessing the quality of educational institutions, Cartter declared quality to be "an elusive attribute, not easily subjected to measurement." According to him, no single index-be it size of endowment, number of 
books in the library, publication record of the faculty, etc.-nor any combination of such measures is sufficient to estimate adequately the true worth of an educational institution. Cartter stated that such "objective" measures of quality are for the most part "subjective" measures once removed, and he concluded, "In an operational sense, quality is someone's subjective assessment, for there is no way of objectively measuring what is in essence an attribute of value."

From this perspective, of the three variables in the chemistry-serials database for measuring scientific value, faculty score is the crucial one, and the other two-total citations and impact factormust be judged by their relationship to faculty score. To do this, the Pearson correlation coefficient of faculty score with both total citations and impact factor was computed after the logarithmic transformation of all the variables recommended by Elliott $(1977,33,102)$ was carried out. Then the correlations were treated as univariate regressions, and the data were analyzed for outliers and inappropriate influential observations, i.e., observations crucial in determining the slope of the regression line. In both cases faculty score was made the dependent variable, because it was assumed to have the most error in it. After the proper exclusions the correlations were then recomputed.

This procedure revealed a strong correspondence of faculty score to total citations. The first Pearson product-moment correlation coefficient between the two variables was 0.66. Analysis of the residuals turned up five outliers, of which four had low faculty scores with respect to their total citations. Of these outliers, two can be attributed at least partly to Garfield's law of concentration and the omission of the LSU Department of Biochemistry from the faculty survey, because these titles were classified by ISI in Biochemistry and Molecular Biology. The fifth outlier was the Journal of Chemical Education, and its faculty score was high with respect to its total citations. This title ranks highest on the variable libraries holding and is generally read more for information than cited for research. When all five outliers were excluded, the Pearson product-moment correlation coefficient between faculty score and total citations rose to $\mathbf{0 . 7 2}$.

All in all, it was a remarkable performance, for, on one side of the bivariate relationship, there was a small, nonrandom sample of local chemistry faculty and, on the other, a good proportion of the entire universe of publishing chemists. The results validate the practice of utilizing local faculty for collection development purposes. Moreover, these results corroborated an earlier finding made by this researcher (Bensman 1985, 22) correlating the total SSCI citations received by economics departments with the peer ratings of these departments by a scientifically selected sample of economics professors in the 1981 assessment of U.S. doctoral programs sponsored by the Conference Board of Associated Research Councils. The Pearson product-moment correlation coefficient was a stunning 0.92 . Together, these two findings confirm the hypothesis that faculty score and total citations are just two different measures for the same variable of scientific value.

However, it is a different story when it comes to the relationship of faculty score to impact factor. In this case the initial Pearson product-moment correlation coefficient was a mere 0.25 . There were two outliers, and, needless to say, confidence in impact factor as a measure of scientific value was not increased by the discovery that one of these outliers was the Journal of the American Chemical Society. When the two outliers were excluded, the Pearson product-moment correlation coefficient between faculty score and impact factor rose to only 0.27 . These results were somewhat disconcerting as ISI gives considerable prominence to impact factor by devoting an entire section of its JCR to listing journals in descending order by this measure within subject categories. Moreover, impact factor is commonly used as a value measure in studies of journal prices (Baldwin and Baldwin 1989; Barschall 1988; Moline 1991; Nisonger 1993; Ribbe 1988).

Analysis of the possible causes for the relatively low correlation between faculty score and impact factor uncovered three 
possible explanations for this phenomenon. As has been explained, impact factor represents an attempt by ISI to create a normalized measure of value by controlling the citation frequency to a journal for size and age to create an average citation rate per article over a recent time period. However, this procedure brings into play an exogenous variable that relates to the average citation rates of different types of articles and might have nothing to do with peer perceptions of value. Literature review articles have approximately double the impact factor of normal journal articles (Moed and Van Leeuwen 1995, 463, table 1), and this type of article might be consulted by scientists more for convenience than for new, significant findings. The SCI JCR for 1993 has a section entithed "Source Data Listing" that presents data on the composition of the source journals in terms of review and nonreview articles. This section was utilized to determine the nature of the top fifteen titles of the chemistry-serials database in impact factor. These titles represent $9.7 \%$ of the titles in the database but account for $40.1 \%$ of the aggregate impact factor of the serials in the database. The "Source Data Listing" had information on twelve of these titles. Of these twelve titles, six were review journals consisting of $100 \%$ review articles, two were overwhelmingly review journals containing respectively $92.9 \%$ and $81.3 \%$ review articles, and two were half review journals consisting respectively of $55 \%$ and $41.2 \%$ review articles. Review articles represented an insignificant proportion of the final two titles.

The other two possible explanations for the relatively low correlation between faculty score and impact factor relate to the very nature of the controls employed by ISI to create the latter measure. Concerning size, academic perceptions of quality or value appear to be greatly and positively influenced by this objective attribute. This phenomenon was observed in the two assessments of U.S. doctoral programs sponsored in 1981 and 1993 by the Conference Board of Associated Research Councils. The 1981 assessment (Jones, Lindzey, and Coggeshall 1982) found that in all subject fields peer per- ception of program quality correlated positively with measures of program size in terms of number of faculty members, students, and recent graduates, noting that the larger the program, the more likely its faculty was to be rated high in quality. Moreover, in the social sciences the 1981 assessment discovered that the influence of size also was operative with regard to faculty publications. For seven academic fields, peer ratings of the quality of program faculty members correlated highly with total articles attributed to these faculty members in journals covered by the SSCI 0.71 in Political Science to 0.80 in Sociology). However, as soon as the publication measure was corrected for size by reporting the fraction of program faculty members with one or more articles, the correlations with peer ratings dropped markedly to a range from 0.26 in Anthropology to 0.59 in Geography.

The findings of the 1981 assessment on the role of size in academic perceptions of quality were confirmed by the 1993 assessment (Goldberger, Maher, and Flattau 1995). In the 1993 assessment it was found that two basic groups of variables correlated strongly with peer ratings of the scholarly quality of program faculty: (1) "size" as defined by number of faculty, students, and graduates and (2) "level of faculty research and scholarship" as measured by publications, citations, and grants. The 1993 assessment noted that the strong positive correlations between the size of a faculty in a program and its reputational standing have not been thoroughly explored. Nevertheless, the same process at work in the 1981 and 1993 assessments of U.S. doctoral programs appeared also to be active with respect to the titles in the chemistry-serials database. After being subjected to the same procedures as the correlations of faculty score with total citations and impact factor, the Pearson coefficient of faculty score with the size measure source items turned out to be 0.59 upon the exclusion of three outliers.

To investigate the other control imposed by ISI to create the measure impact factor, the effect of serial age on peer ratings was analyzed. This analysis was 
also intended to test the assumption that the faculty would esteem more highly the older, more established journals. Serial age appears to influence peer ratings much less than serial size. When faculty score was correlated with journal age in the manner outlined above, the initial Pearson correlation coefficient was 0.24 . There proved to be three outliers, but, unlike the preceding examples, all the outliers were also found to be influential observations able to affect the correlation coefficient out of proportion to their representation in the database. Upon investigation the three influential outliers turned out to be European journals over one hundred years old with the lowest possible faculty score of 10 and titles in a foreign language. Needless to say, their faculty scores were low in comparison to their total citations, further proving that these titles were not in the mainstream of U.S. chemistry. When excluded from the computations, the Pearson product-moment correlation coefficient between faculty score and journal age increased from 0.24 to 0.34 , or by more than $41 \%$.

Further investigation of the effect of serial age and size on peer ratings was done by regressing faculty score on source items and journal age. During the analyses conducted to decide upon the final form of the regression equation, there were discovered not only three outliers related to extremes in source items but also five influential observations that were deemed inappropriate even though they were not outliers. Three of these influential observations had appeared as influential outliers in the correlation of faculty score with journal age above, whereas the other two influential observations belonged to the same category, being European and over one hundred years old. Because the five influential observations appeared to be more in the European than in the American tradition of chemistry, it was decided to exclude them along with the three outliers related to size. With this done, the total variance in faculty score caused by its regression on source items and journal age was $46 \%$. However, there was a considerable amount of overlap in the effect of size and age. source items by itself accounted for $44 \%$ of the variance in faculty score and $31 \%$ of the variance over and above that of journal age, whereas journal age by itself accounted for $15 \%$ of the variance in faculty score but merely $2 \%$ of the variance over and above that of source items. These results seem natural, because part of the size of a journal is its backfile, which is also an expression of its age. Due to all these considerations, it was decided to reject impact factor as a valid measure of scientific value.

\section{The Structure of The Library MARKeT For Chemistry Journals}

It was decided to begin the exploration of the structure of the library market for chemistry journals by comparing the major groups composing it. These groups are defined by the categorical variables publisher type and country of origin. As described above, the first of these categorical variables divides the journals into association and commercial ones, whereas the second of these categorical variables divides them into U.S. and foreign journals. These groups were compared by testing whether there were significant differences between them in the means of the quantitative variables being used to measure the market. Given the highly skewed distributions of the quantitative variables, the nonparametric Wilcoxon rank sum test was performed to determine whether the differences between the means were significant. The results of the comparisons are summarized in table 2. With respect to publisher type, it can be seen that association journals are approximately half as expensive, score 2.7 to 3.4 times higher on measures of scientific value, contain 2.2 more articles, and are held by 2.1 times more libraries than commercial journals. Moreover, all the differences between the means are highly significant. However, the situation is not so clear-cut when it comes to country of origin. At first glance the U.S. joumals appear to have the advantage over the foreign ones, but closer inspection reveals that the differences between the means are significant in only two cases: (1) price, U.S. journals are half as expensive, and (2) libraries holding, 
U.S. journals are held by 1.6 more libraries. Even the latter advantage seems to dissipate when it is remembered that U.S. libraries form the overwhelming bulk of the members of the OCLC network, from which the libraries holding data were taken.

For this paper the major tool to analyze the structure of the library market for chemistry journals was a general linear regression equation, which was preliminarily specified in the following two models:

\section{Model 1:}

price $=b_{0}+b_{1}$ (publisher type)

$+b_{2}$ (country of origin) $+b_{3}$ (faculty score $)+b 4($ source items $)+b 5$ (libraries holding)

Model 2:

price $=b_{0}+b_{1}($ publisher type $)$

$+b_{2}$ (country of origin) $+b_{3}$ (total citations) $+\mathrm{b}_{4}$ (source items)

+ b5(libraries holding)

The two models are identical except that in model 1 faculty score is used as the measure of scientific value, whereas in model 2 total citations serves as the measure of scientific value. Because faculty score and total citations were considered in theory as basically equivalent measures and were highly correlated, it was expected that their effects would be similar.

Both models have the purpose of determining the role of publisher type, na- tional origin, scientific value, size, and the number of copies sold to libraries in the pricing of chemistry journals. As a result of the literature review and preliminary data exploration, the hypotheses were set that commercial journals would cost more than association ones and that foreign serials would be priced higher than domestic ones. Therefore, the dummy variables publisher type and country of origin were coded in such a way that their coefficients would be positive if these hypotheses were true. Moreover, it was also posited that scientific value as measured by faculty score and total citations would positively affect prices even if only because it seemed to be in the publishers' self-interest to make as inelastic as possible the library demand for the more expensive journals. As a matter of fact, it was even considered likely that scientific value would play such a role in journal pricing that libraries would be trapped within the locked system described at the beginning of the paper. Size as measured by source items in terms of numbers of citable units was also thought to have a positive effect on prices, because larger joumals were deemed more costly to produce. On the other hand, the variable libraries holding was hypothesized to have a negative regression coefficient as the cost per copy was assumed to decrease in line with the number of copies able to be printed and sold.

TABLE 2

\section{Comparison of Variable Means by Publisher Type and Country of Origin}

\begin{tabular}{lcccrr}
\hline \hline & \multicolumn{5}{c}{ Means } \\
& Price & $\begin{array}{c}\text { Faculty } \\
\text { Score }\end{array}$ & $\begin{array}{c}\text { Total } \\
\text { Citations }\end{array}$ & $\begin{array}{c}\text { Source } \\
\text { Items }\end{array}$ & $\begin{array}{r}\text { Libraries } \\
\text { Holding }\end{array}$ \\
\hline Publisher Type & & & & & \\
Association $N=34$ & 720.71 & 177 & 28,218 & 780 & 719 \\
Commercial $N=119$ & $1,346.00$ & 66 & 8,198 & 353 & 339 \\
$P$-value* & 0.0002 & 0.0003 & 0.0224 & 0.0082 & 0.0001 \\
Country of Origin & & & & & \\
United States $N=67$ & 747.56 & 113 & 16,727 & 493 & 541 \\
Foreign $N=87$ & $1,559.67$ & 75 & 9,960 & 424 & 333 \\
$P$-value & 0.0001 & 0.8368 & 0.9811 & 0.9506 & 0.0012 \\
\hline
\end{tabular}

-Difference between the means is statistically significant if $p$-value is below 0.05 . 
Exploratory computer runs of both models of the general linear regression equation immediately revealed major problems with the equation's functional specification resulting from the highly skewed distribution of the variables. These problems were of such a nature as to cause the violation of a number of the classical assumptions of linear regression. First of all, examination of the plots of the residuals against the predicted values of the dependent variable price showed that the regression function was not linear, and the constantly accelerating increases of the prices of the journals in the sample suggested that some sort of exponential relationship existed between the dependent and independent variables of the equation. Moreover, the same residual plots revealed that the error terms did not have a constant variance but were heteroscedastic, increasing as the dependent variable price increased. Heteroscedasticity is a danger inherent in studies involving the comparison of groups (Hardy 1993, 53-56). Finally, tests revealed that the error terms were not normally distributed. Due to these violations of the classical linear regression assumptions, it was necessary to perform a transformation in order to introduce additivity into the equation as well as to stabilize the variability and normalize the distribution of the error terms (Acton 1959, 219-23). Elliott (1977, 33, 102-3) calls for a logarithmic transformation, and the most frequent procedure is to transform the dependent variable (Sokal and Rohlf 1981, 539-41). The variable price was accordingly subjected to the logarithmic transformation, and this conversion of the equation to the semilogarithmic form corrected the above violations of the classical regression assumptions.

With the main methodological problems solved, it was decided to analyze the structure of the library market for chemistry journals in three phases. The first phase was to investigate the role of all the independent variables together in determining price with the full regression equation. In the second phase the chemistry journals were segregated by publisher type to determine whether association and commercial publishers operated differently in the pricing of their journals. The third phase was to separate the journals by country of origin for the purpose of analyzing the pricing policies of U.S. and foreign publishers. In all phases both models-model 1 using faculty score and model 2 utilizing total citations - of the regression equations were run. The semilogarithmic form with the transformation of the dependent variable was the proper functional specification in all cases.

Multicollinearity was investigated, but none was found. Before the final computer runs, the residuals were again examined for outliers needing to be excluded. Four serials appeared as outliers, of which three were so by subject due to omissions in the faculty survey. Two of these subject outliers were classed by ISI in Biochemistry and Molecular Biology and appeared repeatedly, whereas one was classified in Chemical Engineering and emerged only once. The fourth outlier was an egregiously priced commercial journal. It was a consistent outlier and formed the apex of the price distribution.

The results of the three phases of the analysis of the structure of the library market for chemistry journals are summarized in tables $3 \mathrm{~A}, 3 \mathrm{~B}$, and $3 \mathrm{C}$. Before these results can be interpreted, the measurements employed in these tables need to be explained. In semilogarithmic equations of the type utilized for this paper, proportional change is derived by taking the antilog of the regression coefficients and then subtracting 1 . However, proportional change must be understood differently depending upon the type of variable. publisher type and country of origin are intercept dummies. Their coefficients do not affect the slope of the regression line, but-when transformed as above-measure in proportional terms how much more or less across the board a group causes the dependent variable to be with respect to some reference group. On the other hand, the quantitative variables faculty score, total citations, source items, and libraries holding have slope coefficients in that they determine the slope of the regression line. When transformed as 
above, these coefficients measure how much compound proportional changeas in compound bank interest-a one unit change in the independent variable causes in the dependent variable (Halversen and Palmquist 1980; Hardy 1993, 56-60; Stundenmund and Cassidy 1987, 6-15, 41-44; Thornton and Innes 1989).

Concerning the other table 3 measurements, beta weights are standardized multiple regression coefficients, which are produced when the data are analyzed in standard score or z-score form. This denotes that all the variables have been standardized to have a mean of 0 and a standard deviation of 1 . With this done, both the dependent and independent variables are measured on the same scale, and it is possible to interpret the absolute value of the beta weights as indicative of the relative importance of the independent variables in explaining the movements of the dependent variable. The measurement Uniqueness Index must be understood in terms of the concept Rsquare. R-square represents the proportion of variance in the dependent variable that is accounted for by the linear combination of the independent variables. However, the proportions of variance caused separately by each independent variable overlap each other, and the Uniqueness Index is the proportion of variance in the dependent variable that is accounted for by a given independent variable above and beyond the variance caused by the other independent variables in the regression equation (Hatcher and Stepanski 1994, 395-408).

With these explanations in mind, it is now possible to interpret the results of the analyses of the structure of the library market for chemistry journals summarized in table 3. Table 3A shows the results of the first phase in which all the journals-association and commercial, U.S. and foreign-were analyzed together. With respect to the dummy variables, the reference group for publisher type is all association (U.S. and foreign) journals, whereas the reference group for country of origin is all U.S. (association and commercial) journals. As was expected, both model 1 with faculty score and model 2

\section{TABLE 3A}

Proportional Change, Beta Weights, and Uniqueness Indexes Obtained in Multiple Regression analyses Predicting Price

All Serials Together

\begin{tabular}{lccc} 
Independent Variables & $\begin{array}{c}\text { Proportional } \\
\text { Change }\end{array}$ & Beta Weights & $\begin{array}{c}\text { Uniqueness } \\
\text { Indexes }\end{array}$ \\
\hline Model 1: Faculty Score Used for Scientific Value R-square & $=0.5987^{\circ} ; N=147$ & \\
Publisher Type & $0.8495^{*}$ & $0.2745^{\circ}$ & $0.0477^{\circ}$ \\
Country of Origin & 0.1995 & 0.0963 & $0.0070^{*}$ \\
Faculty Score & 0.0014 & 0.1553 & 0.0092 \\
Source Items & $0.0012^{\circ}$ & $0.6746^{\circ}$ & $0.2615^{*}$ \\
Libraries Holding & $-0.0014^{*}$ & $-0.4714^{*}$ & $0.1103^{*}$ \\
Model 2: Total Citations Used for Scientific Value R-square $=0.5896^{\circ} ; N=147$ & \\
Publisher Type & $0.7854^{*}$ & $0.2588^{*}$ & $0.0430^{*}$ \\
Country of Origin & 0.2000 & 0.0966 & 0.0070 \\
Total Citations & -0.000001 & -0.0201 & 0.0001 \\
Source Items & $0.0014^{*}$ & $0.7579^{\circ}$ & $0.1390^{*}$ \\
Libraries Holding & $-0.0012^{*}$ & $-0.4020^{*}$ & $0.0941^{*}$ \\
\hline
\end{tabular}

-Significant at the 0.05 level. 
produced similar results. In neither case did scientific value play a significant role in the prices libraries paid for chemistry journals. Moreover, in both models country of origin also did not play a significant role in determining price, but publisher type did. On the whole, libraries paid $85 \%$ more for commercial journals than for association ones with faculty score and $79 \%$ more with total citations. The variables source items and libraries holding acted as hypothesized. In both models libraries paid about $0.1 \%$ more compounded for each citable unit and approximately $0.1 \%$ less compounded with every subscribing library.

Examination of the beta weights revealed a similar order of importance for the three significant independent variables in each model. With both faculty score and total citations, size in terms of source items was the most determinant of price; number of copies sold in terms of libraries holding was the next most determinant; and publisher type was the least determinant of price. The beta weights findings were confirmed by the uniqueness indexes. Both models had similar Rsquare measures, with model 1 accounting for $60 \%$ of the variance in price and model 2 for $59 \%$. The amount of unique variance accounted for by the three significant independent variables conformed to the order marked out by the beta weights. However, size in terms of source items accounted for almost double the unique variance in price in the faculty score equation than with the total citations equation-26\% to $14 \%$.

The results of the first phase of the analysis of the library market for chemistry journals were largely corroborated by the second phase of the analysis, whose findings are presented in table $3 \mathrm{~B}$. In the second phase the journals were segregated by publisher type, and the two sets of journals were analyzed independently with both models of the equation. With respect to the dummy variable country of origin, in the association set the reference group was the U.S. association publishers, whereas in the commercial set the reference group was the U.S. commercial publishers. Without going into detail, it can be seen that in all cases neither national origin nor scientific value-whether measured by faculty score or total citationsplayed a significant role in the prices paid by libraries for chemistry journals. Moreover, in all cases size and number of copies sold to libraries acted in the hypothesized manner, with the former raising prices and the latter lowering prices. Finally, in all cases size was more important than number of copies sold to libraries in setting prices. When the results of the first phase are taken into consideration with those of the second phase, association and commercial publishers appear to have priced their chemistry journals in the same manner except that the commercial publishers priced theirs at a higher level. In the light of the findings of the third phase of the chemistry-journal market analysis, it is also important to note that U.S. commercial publishers acted no differently in their pricing policies than did foreign commercial publishers.

The third phase of the analysis of the library market for chemistry journals proved to be the most illuminating in many respects. Its results are shown in table 3C. In the third phase the serials were divided into two sets by country of origin, and these sets were analyzed independently from each other with both models of the regression equation. Concerning the dummy variable publisher type, for the U.S. journals the reference group was U.S. association journals, whereas for the foreign journals the reference group was foreign association journals.

With respect to the U.S, set, the results produced by model 1 of the regression equation with faculty score and model 2 with total citations were interesting for both their similarities and their differences. As for their similarities, with both models the dummy variable publisher type was a significant determinant of price, and in each case libraries paid considerably more- $-80 \%$ more with faculty score, $77 \%$ more with total citations-for U.S. commercial journals than for U.S. association ones. These figures are equivalent to those produced for publisher type by the full regression equation in table $3 \mathrm{~A}$, and it shows that the prices of 
TABLE 3B

Proportional Change, Beta Weights, and Uniqueness Indexes Obtained in Multiple Regression Analyses Predicting Price

\begin{tabular}{|c|c|c|c|}
\hline \multicolumn{4}{|c|}{ Serials Segregated by Publisher Type } \\
\hline Independent Variables & $\begin{array}{l}\text { Proportional } \\
\text { Change }\end{array}$ & Beta Weights & $\begin{array}{l}\text { Uniqueness } \\
\text { Indexes }\end{array}$ \\
\hline \multicolumn{4}{|c|}{ Association Serials } \\
\hline \multicolumn{4}{|c|}{ Model 1: Faculty Score Used for Scientific Value R-square $=0.7506^{\circ} ; N=34$} \\
\hline Country of Origin & 0.4174 & 0.1512 & 0.0208 \\
\hline Faculty Score & 0.0008 & 0.1406 & 0.0070 \\
\hline Source Items & $0.0010^{\circ}$ & $0.8327^{\circ}$ & $0.3869^{\circ}$ \\
\hline Libraries Holding & $-0.0009^{\circ}$ & $-0.4410^{\circ}$ & $0.1050^{\bullet}$ \\
\hline \multicolumn{4}{|c|}{ Model 2: Total Citations Used for Scientific Value R-square $=0.7466^{\circ} ; N=34$} \\
\hline Country of Origin & 0.3612 & 0.1337 & 0.0172 \\
\hline Total Citations & 0.000003 & 0.1145 & 0.0029 \\
\hline Source Items & $0.0009^{*}$ & $0.8019^{\circ}$ & $0.1483^{*}$ \\
\hline Libraries Holding & $-0.0008^{\circ}$ & $-0.3843^{\circ}$ & $0.1194^{\circ}$ \\
\hline \multicolumn{4}{|c|}{ Commercial Serials } \\
\hline \multicolumn{4}{|c|}{ Model 1: Faculty Score Used for Scientific Value R-square $=0.5381^{\circ} ; N=115$} \\
\hline Country of Origin & 0.0700 & 0.0351 & 0.0011 \\
\hline Faculty Score & 0.0025 & 0.1657 & 0.0159 \\
\hline Source Items & $0.0014^{\circ}$ & $0.6352^{\circ}$ & $0.2557^{\circ}$ \\
\hline Libraries Holding & $-0.0019^{\circ}$ & $-0.4374^{\circ}$ & $0.1503^{\circ}$ \\
\hline \multicolumn{4}{|c|}{ Model 2: Total Citations Used for Scientific Value R-square $=0.5222^{\circ} ; N=115$} \\
\hline Country of Origin & 0,1040 & 0.0513 & 0.0025 \\
\hline Total Citations & 0.0000004 & 0.0059 & 0.00001 \\
\hline Source Items & $0.0016^{\circ}$ & $0.7128^{\circ}$ & $0.1209^{\circ}$ \\
\hline Libraries Holding & $-0.0017^{\star}$ & $-0.3935^{\circ}$ & $0.1048^{\circ}$ \\
\hline
\end{tabular}

-Significant at the 0.05 level.

U.S. commercial publishers for chemistry journals were in line with those of foreign commercial publishers.

Concerning their differences, with faculty score as the measure, scientific value had a significant and positive effect on prick, but this result was negated when total citations were employed as the measure, and scientific value again reverted to having no significant influence on price. The variables source items and libraries holding yielded a mixed bag of similarities and differences. Both variables performed according to expectations as prices increased with size and decreased with number of copies sold to libraries. However, in model 1 libraries holding had both a higher beta weight and uniqueness index than source items, reversing the usual order of importance for these variables, whereas in model 2 libraries holding had a lower beta weight but higher uniqueness index than source items, producing a confusing picture. All in all, when the national origin of the faculty raters and the majority of the OCLC holding libraries are taken into account, this analysis of U.S. chemistry journals suggests that U.S. publishers might be somewhat attentive to opinions and needs of the U.S. aca- 
TABLE 3C

Proportional Change, Beta Weights, and Uniqueness Indexes in Multiple Regression Analyses Predicting Price

Serials Segregated by Country of Origin

\begin{tabular}{|c|c|c|c|}
\hline Indlependent Variables & $\begin{array}{c}\text { Proportional } \\
\text { Change }\end{array}$ & Beta Weights & $\begin{array}{l}\text { Uniqueness } \\
\text { Indexes }\end{array}$ \\
\hline
\end{tabular}

U.S. Serials

Model 1: Faculty Score Used for Scientific Value R-square $=0.5093^{\circ} ; N=64$

$\begin{array}{llll}\text { Publisher Type } & 0.7992^{\circ} & 0.3158^{\circ} & 0.0728^{\circ} \\ \text { Faculty Score } & 0.0035^{\circ} & 0.5229^{\circ} & 0.1004^{\circ} \\ \text { Source Items } & 0.0007^{\circ} & 0.5220^{\circ} & 0.1639^{*} \\ \text { Libraries Holding } & -0.0018^{\circ} & -0.7532^{*} & 0.2673^{*}\end{array}$

Model 2: Total Citations Used for Scientific Value R-square $=0.5898^{\circ} ; \mathrm{N}=63$

$\begin{array}{lccl}\text { Publisher Type } & 0.7725^{\circ} & 0.3152^{*} & 0.0739^{\circ} \\ \text { Total Citations } & -0.000003 & -0.0951 & 0.0017 \\ \text { Source Items } & 0.0015^{*} & 0.8689^{\circ} & 0.1395^{*} \\ \text { Libraries Holding } & -0.0013^{\circ} & -0.5705^{\circ} & 0.2168^{\circ}\end{array}$

Foreign Serials

Model 1: Faculty Score Used for Scientific Value R-square $=0.5115^{\circ} ; \mathrm{N}=84$

$\begin{array}{lccc}\text { Publisher Type } & 0.8168 & 0.1625 & 0.0229 \\ \text { Faculty Score } & 0.0010 & 0.0759 & 0.0030 \\ \text { Source Items } & 0.0012^{\circ} & 0.7280^{\circ} & 0.3178^{\circ} \\ \text { Libraries Holding } & -0.0010^{\circ} & -0.2050^{\circ} & 0.0256^{\circ}\end{array}$

Model 2: Total Citations Used for Scientific Value R-square $=0.5097^{\circ} ; \mathrm{N}=84$

$\begin{array}{llll}\text { Publisher Type } & 0.8283 & 0.1642 & 0.0232 \\ \text { Total Citations } & 0.00001 & 0.0957 & 0.0012 \\ \text { source items } & 0.0012^{\circ} & 0.6853^{\circ} & 0.0720^{\circ} \\ \text { Libraries Holding } & -0.0009 & -0.1990 & 0.0220\end{array}$

- Significant at the 0.05 level.

demic community.

When the third phase of the analysis of the library market for chemistry journals was turned to the set of foreign serials, the variables for the most part resumed the same basic pattern as in the first two phases with one notable exception. Concerning the basic pattern, in neither the form of faculty score nor of total citations was scientific value a significant determinant of price. Both models showed size in number of source items as playing the major role in causing some journals to cost more than the others. The variable libraries holding had contradictory outcomes, having a significant effect on price in model 1 but not being significant in model 2. However, libraries holding did not miss being significant by much $(p=0.06)$ in model 2 . The one notable exception concerned the variable publisher type, which was not significant for the overall level of price in either model. Given the previous findings, this result was so startling that it prompted a reexamination of the basic data. An answer was readily found.

Of the 67 U.S. journals in the chemistry-serials database, 29 were published by associations, and of these 29 association journals, 20 were put out by the American 

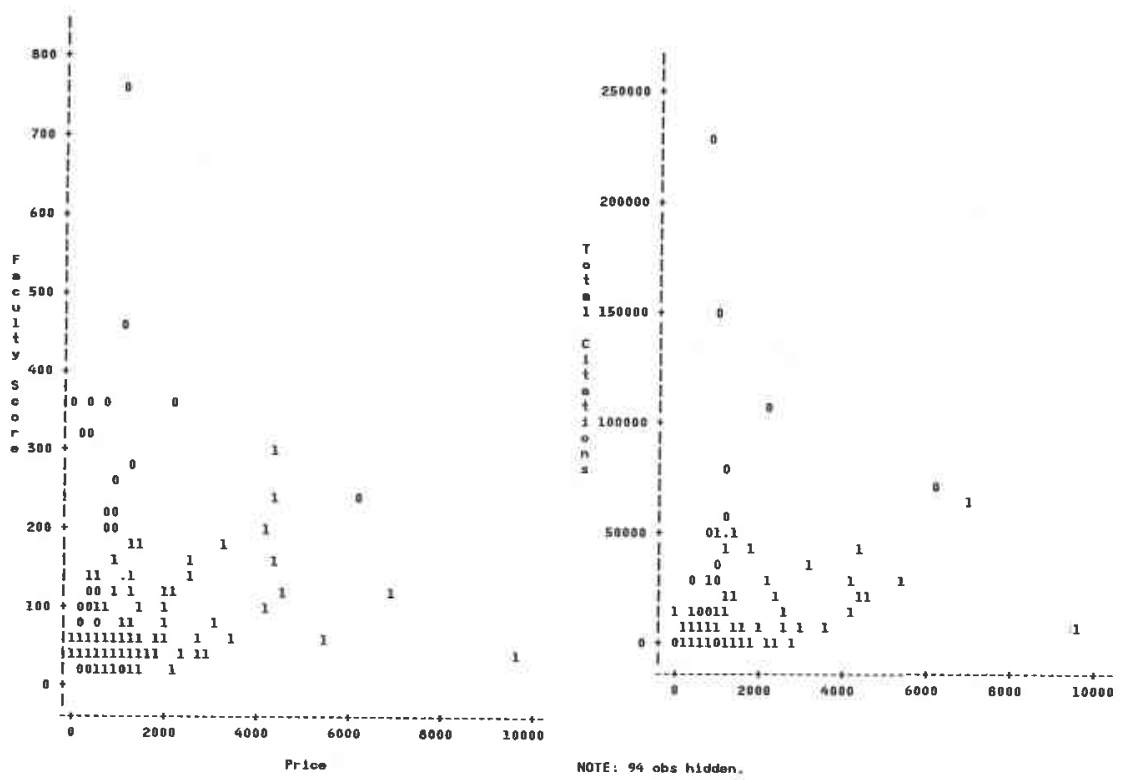

NOTE: 66 abs hidden.

Figure 2. Publisher Structure of Library Market for Chemistry Journals (Association Publishers Designated by 0s; Commercial Publishers Designated by 1s)

Chemical Society. In contrast, of the 87 foreign journals in the database, only 5 were published by associations-one by the National Research Council in Canada and 4 by the Chemical Society in Britain. All the remaining serials in both groups were commercial journals except for one foreign journal published by a university press. Moreover, the British Chemical Society charges like a commercial publisher for its major publication. When all five sections were combined, the Journal of the Chemical Society ranked third in price of the 154 serials in the database, and it cost $\$ 1.94$ per ISI Source item in 1993. In comparison, the Journal of the American Chemical Society cost only $\$ 0.46$ per Source Item in that same year. Outside of Britain, Canada, and the United States, the standard pattern for journals issued under association auspices was to be handled by a commercial publisher. Given the above considerations and that U.S. commercial publishers charge like foreign ones, there is a major dichotomy in the library market for chemistry journals be- tween largely U.S. association journals, on the one hand, and all commercial journals, on the other.

Simply conceived, a market occurs when values are exchanged among entities. In the library market for chemistry journals, libraries exchange money presumably for scientific value. To obtain a picture of this market, both measures of scientific value-faculty score and total citations-were plotted against price, producing similar patterns. These plots are shown in figures 2 and 3.

For analysis of the publisher structure of the market, in figure 2 association journals are designated by " 0 " and commercial journals by "1." For examination of the national structure of the market, in figure 3 U.S. journals are designated by " 0 " and foreign journals by " 1 ," The plots reveal graphically three major characteristics of the library market for chemistry journals. First, this market bifurcates into two groups. On the one hand, running parallel to the faculty score/total citations axes, there is what might be called the "high- 


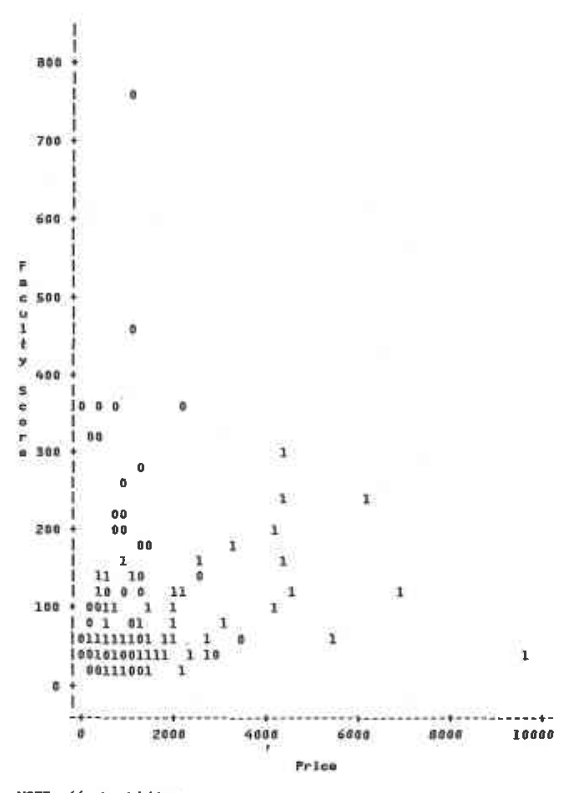

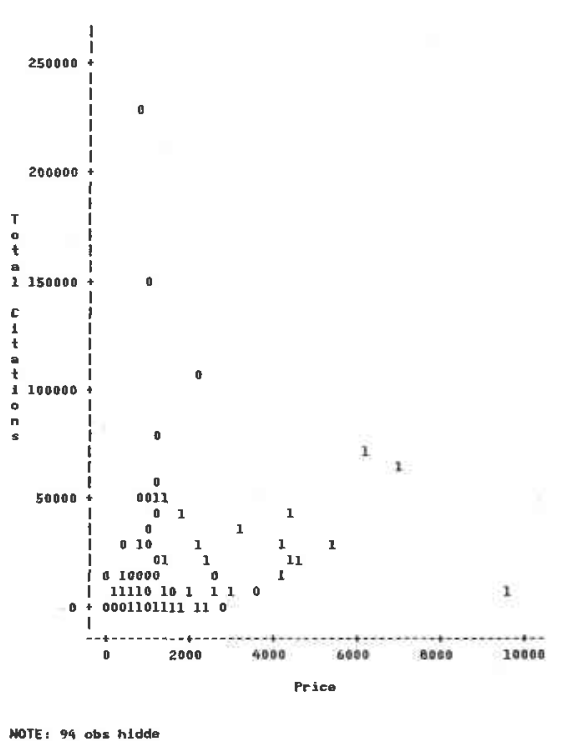

NOTE : 94 obs hidde

NOTE: 66 abs hiddon.

Figure 3. National Structure of Library Market for Chemistry Journals (U.S. Journals Designated by 0s; Foreign Journals Designated by 1 s)

value" group, where scientific value is more than warranted by prices, and the bulk of the scientific value is concentrated due to the skewed distribution of the variables. On the other hand, running roughly parallel to the price axis, there is what might be termed the "high-cost" group, in which prices are higher than justified by scientific value and costs are concentrated. Second, U.S. association journals compose the vast majority of the serials in the high-value group, determining its nature, whereas foreign commercial journals make up the lion's share of the highcost group. However, given the consistent lack of statistical significance for the dummy variable country of origin, the U.S. journals are in the high-value group not because they are U.S. journals but because they are association ones, and the foreign journals are in the high-cost group not because they are foreign but because they are mainly commercial journals. Third, from the perspective of the library market for chemistry journals as a whole, while neither U.S. associations nor com- mercial publishers take scientific value into account when pricing their journals, the former charge too little for scientific value, and the latter, too much.

\section{Practical IMPLications OF THE STRUCTURE OF THE LIBRARY MARKET FOR CHEMISTRY JOURNALS}

The distributions of the variables measuring price and scientific value in the chemistry-serials database appear to belong to the same mathematical family-the negative binomial-and, therefore, have the same highly skewed pattern. However, here the resemblance ends, and the divergence begins. Fundamental to this divergence are the dissimilar causes underlying the skewed nature of the scientific value and price distributions. Whereas the high rating of some journals by peer opinion and the concentration of citations on these journals can be interpreted as resulting from a cumulative advantage process or a success-breeds-success mechanism based upon the social stratification 
of science (Bensman 1982; Bensman 1985), the origins of the skewed distribution of prices lie elsewhere. In the latter case the major roles are played by the different pricing policies of the commercial versus the U.S. association publishers and the size of the journals. There must be added to this mixture, in my opinion, an element of larceny on the part of one foreign commercial publisher, whose egregiously priced chemistry journal formed the apex of the price distribution and was a consistent outlier due to its cost and value being so flagrantly out of line. Any chance for the prices of the chemistry journals in the database for this paper to derive from the same cumulative advantage process as their scientific value was negated by the negligible role scientific value played in their pricing.

The major practical conclusion from the divergence of the price and scientific value distributions is that libraries are not caught in the locked system described at the beginning of this paper but are in a position to implement a massive restructuring of their serials collections. If journals in other subject areas bifurcate in the same way as in chemistry, and if one operates on the assumption that in times of budgetary stringency libraries should subscribe to the best journals and provide only remote access through document delivery to the others, then the opportunity exists for libraries to downsize their serials collections in a significant way. To test this possibility, a software package called the Serials Evaluator has been developed at Louisiana State University. Based upon a Statistical Analysis Software (SAS) platform, the Serials Evaluator incorporates the statistical principles presented in this paper and analyzes sets of journals within subject classes by comparing their prices to their utility measures. These utility measures are of the three following types: (1) numerical indexes derived from surveys of the local faculty and experts; (2) ISI citation data; and (3) usage data gathered from library automation systems. A model of the Serials Evaluator utilizing the manual input of data has been completed, and it is intended to interface the Serials Evaluator to the LSU NOTIS sys- tem for the automatic retrieval of subject, price, and usage information.

For experimental purposes, the Serials Evaluator was utilized to explore the possibilities of downsizing the set of 154 chemistry journals in the database for this paper. In the experiment both faculty score and total citations were employed as utility measures. The Serials Evaluator offers a choice of two basic algorithms. Envisioned for use by small departmental or special libraries, one algorithm exploits the full divergence of price from scientific value by proposing for cancellation all journals whose percentage of total cost exceeds its percentage of total utility.

With faculty score as the utility measure, the Serials Evaluator designated for elimination 83 titles for a total cost reduction of $79 \%$ and a total utility loss of $34.8 \%$, whereas, with total citations as the utility measure, the Evaluator selected for cancellation 105 titles for a total cost reduction of $77.1 \%$ and a total utility loss of $27.4 \%$. Due to the high correlation between faculty score and total citations, there was a considerable amount of overlap, and 69 titles were common to both the faculty score and total citations cancellation lists.

The other basic algorithm offered by the Serials Evaluator is to allow the user to set goals in terms of cost reduction and utility retention. In this algorithm the Serials Evaluator forms two different setsone from the journals with the highest prices, another from the journals with the highest utility-and then compares these sets to select for cancellation only those high-price journals that are not in the high-utility set. In the experiment with the chemistry-serials database, the default value $75 \%$ was utilized for both cost reduction and utility retention. Using faculty score as the utility measure, the Serials Evaluator listed 30 titles whose elimination would result in a $34.1 \%$ reduction in total cost with a mere $9.2 \%$ in total utility. With total citations as the utility measure, the Serials Evaluator named 37 journals whose cancellation would reduce total costs by $40.8 \%$ with only a $10.3 \%$ loss in total utility. There was again a considerable amount of overlap, and 26 titles were 
on both the faculty score and total citations cancellation lists. Of great interest was the finding that when the titles on subscription at the LSU Chemistry Library in 1993 but not named by the faculty in the survey were weeded for those either not covered by the SCI or classed by ISI in nonchemistry subject groups as well as in only Biochemistry and Molecular Biology or Chemical Engineering, 49 journals costing $\$ 32,406.43$ at 1993 prices remained to be considered for cancellation.

\section{WORKS CITED}

Acton, Forman S. 1959. Analysis of straightline data. New York: Wiley.

Alexander, Adrian W., and Kathryn Hammell Carpenter. 1995, U.S. periodical price index for 1995. American libraries 26: 446-54.

Association of Research Libraries. 1989. Report of the ARL serials prices project. Washington, D.C.: ARL.

Baldwin, Jane, and W. M. Baldwin. 1989. Let the buyer be aware: High price does not necessarily mean high quality. Advances in serials management 3 : 111-29.

Barnett, Vic. 1978. The study of outliers: Purpose and model. Applied statistics 27, no. 3: 242-50.

Barnett, Vic, and Toby Lewis. 1984. Outliers in statistical data. 2 d ed. Chichester, Eng.: Wiley.

Barschall, Henry H. 1988. The cost-effectiveness of physics journals. Physics today 41: 56-59.

Bensman, Stephen J. 1982. Bibliometric laws and library usage as social phenomena $\mathrm{Li}$ brary research 4: 279-312.

—_ 1985. Journal collection management as a cumulative advantage process. College \& research libraries 46 : 13-29.

Cartter, Allan M. 1966. An assessment of quality in graduate education. Washington, D.C.: American Council on Education.

Dougherty, Richard M, and Brenda L. Johnson. 1988. Periodical price escalation: A library response. Library journal 113: 27-29.

Dougherty, Richard M., and Nancy E. Barr, 1988. Paying the piper: ARL libraries respond to skyrocketing journal subscription prices. Journal of academic librarianship 14: 4-9.

Elliott, J. M. 1977. Some methods for the statistical analysis of samples of benthic invertehrates. $2 \mathrm{~d}$ ed. Freshwater Biological
Association Scientific publication, no. 25. Ambleside, Eng.: Freshwater Biological Assoc.

Garfield, Eugene. 1979. Citation indexing: Its theory and application in science, technology, and humanities. Philadelphia: ISI Press.

Goldberger, Marvin L., Brendan A. Maher, and Pamela Ebert Flattau, eds. 1995. Research-doctorate programs in the United States: Continuity and change. Washington, D.C.: National Academy Press.

Halvorsen, Robert, and Raymond Palmquist. 1980. The interpretation of dummy variables in semilogarithmic equations. American economic review 70: 474-75.

Hamaker, Charles. 1987. Serials costs and the carrying ability of serials budgets 1987 . Serials librarian 13: 129-34.

__ 1988. Library serials budgets: Publishers and the twenty percent effect. $L i$ brary acquisitions 12: 211-19.

Hardy, Melissa A. 1993. Regression with dummy variables. Quantitative applications in the social sciences, 93. Newbury Park, Calif.: Sage.

Hatcher, Larry, and Edward J. Stepanski. 1994. A step-by-step approach to using the SAS system for univariate and multivariate statistics. Cary, N.C.: SAS Institute.

Jones, Lyle V., Gardner Lindzey, and Porter E. Coggeshall, eds. 1982. An assessment of research-doctorate programs in the United States, 5 vols. Washington, D.C.: National Academy Press.

Lotka, Alfred J. 1926. The frequency distribution of scientific productivity. Joumal of the Washington Academy of Sciences 16: 317-23.

Merton, Robert K. 1968. The Matthew Effect in science. Science 159: 56-63.

Moed, H. F., and Th. N. Van Leeuwen. 1995. Improving the accuracy of Institute for Scientific Information's impact factors. Journal of the American Society for Information Science 46: 461-67.

Moline, Sandra R. 1991. Mathematics Journals: Impact factor and cents per thousand characters. Serials librarian 20, no. 4: 6571.

Nisonger, Thomas E. 1993. The relationship between price and citation data for journals in two subject areas. Proceedings of the ASIS annual meeting 30: 151-59.

OCLC. n.d. Furthering access to the world's information: OCLC annual report: 199394. Dublin, Ohio: OCLC Online Computer Library Center, Inc.

Price, Derek de Solla. 1976. A general theory 
of bibliometric and other cumulative advantage processes. Journal of the American Society for Information Science 27: 292306.

Ribbe, Paul H. 1988. Assessment of prestige and price of professional publications. American mineralogist 73: 449-69.

Rice, Barbara A. 1979. Science periodicals use study. Serials librarian 4: 35-47.

Science Citation Index Journal Citations Reports. 1993. Philadelphia: Institute for Scientific Information.

Small, Henry, and Eugene Garfield. 1985. The geography of science: Disciplinary and national mappings. Journal of information science 11: 147-59.

Sokal, Robert R., and F. James Rohlf. 1981. Biometry. 2d ed. San Francisco: W. H. Freeman.

Stankus, Tony, and Barbara A. Rice. 1982. Handle with care: Use and citation data for science journal management. Collection management 4, nos. 1/2: 95-110.

Stundenmund, A. H., and Henry J. Cassidy. 1987. Using econometrics: A practical guide. Boston: Little, Brown.

Thornton, Robert J., and Jon T. Innes. 1989. Interpreting semilogarithmic regression coefficients in labor research. Journal of labor research 10: 443-47. 